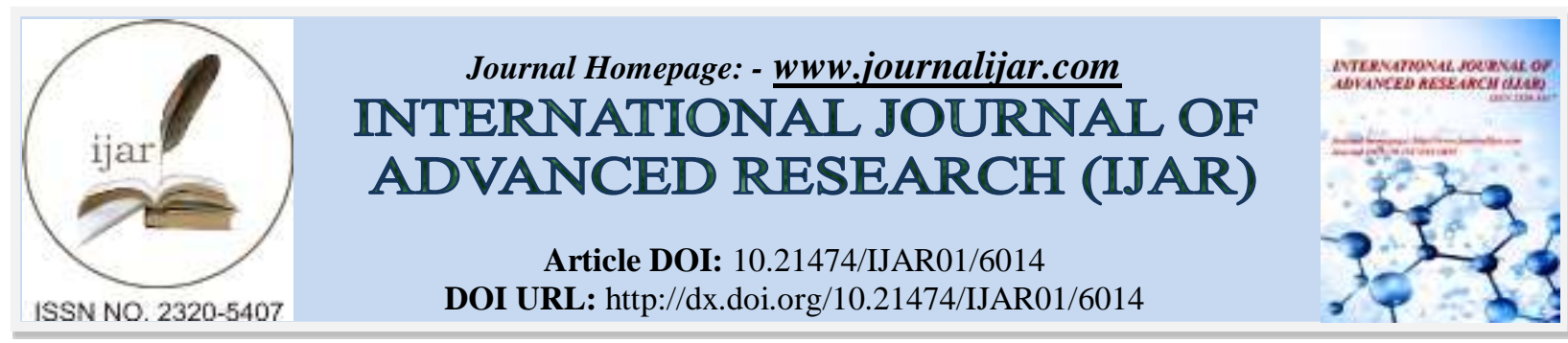

RESEARCH ARTICLE

\title{
AN ASSESSMENT OF MULTI-PLATE SCREW PRESS IN DEWATERING PROCESS OF SLUDGE TREATMENT (the best option?).
}

\section{Anne Wambui Mumbi ${ }^{1}$, Li Fengting ${ }^{2}$, Fridah Mwarania ${ }^{3}$ and Batzorig Uuganchimeg ${ }^{4}$.}

1. UNEP- TONGJI Institute of Environment for Sustainable Development, College of Environmental Science and Engineering, Tongji University, Shanghai.

2. UNEP-TONGJI Institute of Environment for Sustainable Development, College of Environmental Sciences and Engineering, State Key Laboratory of Pollution Control and Resource Reuse, Tongji University, Shanghai, P. R.China.

3. UNEP- TONGJI Institute of Environment for Sustainable Development, College of Environmental Science and Engineering, Tongji University, Shanghai.

4. UNEP- TONGJI Institute of Environment for Sustainable Development, College of Environmental Science and Engineering, Tongji University, Shanghai.

\section{Manuscript Info}

Manuscript History

Received: 09 October 2017

Final Accepted: 11 November 2017

Published: December 2017

Dewatering; Industries; multi-plate

Screw Press; Sludge; Wastewater.

Mechanical equipment.
Key words:-

\begin{abstract}
Sludge dewatering is a crucial step in sludge treatment because it determines the amount of and quality of sludge produced. There are many mechanical methods of dewatering sludge. The paper aims at analyzing three major methods based on principle of operation and possible optimization techniques then compares it to multi-plate screw press which is being adapted as a model that aims at solving problems that arise from usage of the fore mentioned equipment while clearly offering energy efficient solutions. Ultimately the question of the best option can be answered after carefully analyzing available literature on other used equipment. The development of Multi-plate Screw Press which is adaptable to deal with sludge from a variety of industries such as petro chemistry, petrochemical chemical fiber, paper-making, pharmaceuticals, leather, food and beverage etc. It is easy to operate and more power efficient. It utilizes the principles of dewatering forcewater homo-direction and thin-layer dewatering. The machine allows automatic continuous operation of sludge flocculation thickening dewatering and filtrate discharging. It is equipped with moving rings that are self-cleaning it utilizes very little power as it relies on a low inner pressure of the filter chamber. Moreover the problem of noise pollution is eradicated as well as space as this technology can be connected directly to the aeration tank or the secondary sedimentation tank.
\end{abstract}

Copy Right, IJAR, 2017,. All rights reserved.

\section{Introduction:-}

In an era where industries mushroom everyday due to upcoming competitve markets it is without a doubt that waste and wastewater production is inevitable. Fortunately there have been a couple of technologies developed in the past

Corresponding Author:- Anne Wambui Mumbi.

Address:- UNEP- TONGJI Institute of Environment for Sustainable Development, College of 740 
centuries to deal with wastewater as well as try to recover resources from the waste water. In the treatment of waste water sludge formation is inevitable. Sludge is usually the layer of suspended solids that forms at the bottom of a sedimentation tank in a water or wastewater treatment process. Sludge formed must be removed from the tank, treated, and dewatered (or dried) before its final disposal. Treatment and dewatering are required to stabilize the sludge and to reduce its volume. Currently, major methods (Technology \& Universit, 2016)available for sludge disposal; incineration and land spreading. For both, a preliminary step of dewatering is usually required.

Due to the large quantities of sewage sludge generated, management of treated sewage sludge, or bio solids, is becoming increasingly important (USEPA, 1999). The composition and characteristics of sludge vary widely. Furthermore, sludge characteristics change considerably with time. Wastewater sludge typically contains organics (proteins, carbohydrates, fats, oils), microbes (bacteria, viruses, protozoa), nutrients (phosphates and nitrates), and a variety of household and industrial chemicals. The higher the level of heavy metals and toxic compounds, the greater is the risk to humans and the environment.

A key physical characteristic is the solids concentration because this defines the volume of sludge that must be handled. It also determines whether the sludge behaves as a liquid or a solid. Sludge tends to act like plastic fluids as the solids concentration increases until a relatively solid state is reached. There are several types of sludge that have specific characteristics that will influence: The choice in conditioning chemical (cationic flocculant, ferric chloride, lime etc.); choice in the dewatering equipment to be used (filtration, centrifuge etc.) and these choices will also depend on the final use of the sludge (incineration, agricultural spreading etc.) Sludge is treated prior to ultimate disposal for two basic reasons: volume reduction and stabilization of organics. Stabilized sludge does not have an offensive odor and can be handled without causing a nuisance or health hazard.(Boráň, Houdková, \& Elsäßer, 2010) A reduced sludge volume minimizes pumping and storage requirements and lowers overall sludge handling costs.(Borán̆ et al., 2010)Several processes are available for accomplishing these two basic objectives. They include sludge thickening, digestion, dewatering, and co-composting. Sludge thickening is a physical process that serves to increase the solids concentration of the sludge. Because sludge volume varies inversely with the solids concentration, doubling the solids content from 3 percent to 6 percent, for example, will cut the total sludge volume in half. Sludge digestion is a process in which biochemical decomposition of the organic solids occurs; in the decomposition process, the organics are converted into simpler and more stable substances. Digestion also reduces the total mass or weight of sludge solids, destroys pathogens, and makes it easier to dry or dewater the sludge. Well digested sludge has the appearance and characteristics of a rich potting soil.(Bourioug et al., 2015)

\section{Sludge Dewatering:-}

Sludge dewatering is a crucial step in waste water treatment. Sludge Dewatering is described as Removing enough water from a liquid sludge to change its consistency to that of moist earth it is also called sludge drying, the "dry" or dewatered sludge may still contain a significant amount of water, often as much as 70 percent.(Floerger, 2003) But at moisture contents of 70 percent or less, the sludge is liftable, that is, it no longer behaves as a liquid and can be handled manually or mechanically. Sludge is usually dewatered prior to land burial or incineration. Several parameters concerning the sludge will influence its ability to dewater easily. Amongst these, the main ones are: Concentration; this determines the incorporation and consumption of the flocculant. The higher the concentration of the sludge, the harder it is to mix in a viscous solution of flocculant (even at low flocculant concentrations). While the higher the concentration of the sludge, the lower the consumption of flocculant. This is true only if the incorporation is correctly done.

The organic matter content's the organic matter content is comparable to the Volatile Solids content (VS). The higher the VS, the more difficult the dewatering. The dryness achieved will be low, the mechanical properties will be low and the flocculant consumption will be high. When the VS of the sludge is high, it is recommended to add a thickening step in the process in order to achieve a better dewatering.

The colloidal nature of the sludge: This characteristic has a very important effect on the dewatering performance. The higher the colloidal nature, the more difficult it is to dewater. Four factors will affect the colloidal nature of the sludge: The origin of the sludge, the freshness of the sludge: the colloidal nature of the sludge will increase with its level of fermentation (septic sludge).The origin of the wastewater: a dairy or brewery origin will increase the colloidal nature of the sludge and the sludge return: a badly controlled return of the sludge will increase its colloidal nature.(Floerger, 2003) 
There have been numerous technologies that have been developed to dewater sludge(Warman \& Termeer, 2005). Depending on the type of waste water under treatment different equipments suit the process. Among the numerous technologies that have been used in the past most have not proved fully efficient. This paper further explains the use of the Multi-plate Screw Press that has been hyped as the better option for sldge dewatering compared to other equipment. (Okada, n.d.) The Multi-plate Screw Press which is adaptable to deal with sludge from a variety of industries such as petro chemistry paper amyloid chemical blue-green algae pectin wastewater inorganic material and so on can be used for various types of waste water in the dewatering processes. This paper aims at looking the different type of equipemnt used in sludge dewatering and assessing what optimization can be done to the equipment.In order to see the efficiency of the Techase Multi plate screw press the paper analyzes the various equipment operating principles and what changes can be done to optimize their operation. (Sparks, 2012)

\section{Literature Review Summary:-}

Dewatering is a physical (mechanical) unit operation used to reduce the moisture content of sludge so that it can be handled and/or processed as a semi-solid instead of as a liquid. Devices commonly used for dewatering include: Rotary Vacuum Filters, Centrifuges, Drying Beds, Lagoons, Filter Presses, Continuous Belt Filter Presses (CBFP'S) and thermal drying. For the purpose of comparison this paper shall focus on three major equipment namely; centrifuges, belt filter presses and plate and frame filter presses and present a table to show their comparison to the multi-plate screw press machine in order to assess their efficiency and performance.("Impact of water pollution on Nairobi river, Kenya," n.d.)

\section{Centrifugation:-}

Centrifugation is the settling of sludges by a centrifuge that uses the gravitational force created by high-speed rotation to separate the solids. Various types of centrifuges are commercially available. Generally, there are two categories: continuous scroll type and continuous bath bottom feed basket (bowl) type (Hagstrom and Mignone, 1978). Feed solids concentration to the centrifuge usually ranges from 2 to $6 \%$, the expected cake dryness is affected by the centrifugal force, feed rate, rate of polymer dosage, raw water quality, floc size and density, and residence time. The water that is removed can be recycled to the plant or properly disposed of. Lime-softening sludge is reported to be easily dewatered by centrifugation because of its high (80 to $85 \%$ ) calcium carbonate content. Albertson and Guidi (1969) reported that when a solid bowl centrifuge was used, a thickened lime sludge could be dewatered to a cake solids concentration of $55 \%$ with 78 to $93 \%$ solids capture. Data from plants using centrifugation showed that the lime cake solids concentrations were in the range of 55 to $70 \%$ solids by weight while alum sludge centrifugation can achieve only 12 to $20 \%$ solids by weight ("Mech Dewater," n.d.)

\section{Pressure Filtration:-}

The pressure filter is basically made up of a number of porous filter plates containing depressions, held vertically in a supporting frame. Each plate face is covered with a proper filter cloth. A common feed hole or multiple holes for the sludge inlet extend through the plates. Under pressure, either by mechanical or hydraulic means, sludge is pumped into the filter through the feed holes to the chambers formed by the depressions between the plates. The liquid seeps through the filter medium, leaving the solids behind between the plates. With continual pumping, sludge cakes form and ultimately fill the chamber. After the filtration cycle, the plates are separated and the dewatered solids fall easily to a discharge conveyance. An automatic cake remover can also be used. Details of pressure filters and operational variables are discussed elsewhere (Fulton, 1976; AWWA, 1978b; Vesilind, 1979).

The pressure filtration process was first applied to water treatment plant sludges in the United States in the mid1960s. Its lack of popularity is due to its cyclical operation. However, the process is popular in Europe. It has been used extensively in the. Chemical industry for dewatering sludges. A number of different kinds of pressure filters are on the market. Pressure filtration has the capacity of producing filter cakes with a relatively high solids concentration and high-quality filtrate in terms of low suspended solids. The process is flexible and fits any operational mode. (Mahmoud, Hoadley, Conrardy, Olivier, \& Vaxelaire, 2016)

Dewatering of alum sludge by pressure filtration is likely to need sludge conditioning to lower the resistance to filtration. This can be done by the addition of lime, polymers, or fly ash. The choice of conditioning agents is based on the costs for each application. Lime is added to alum sludge to raise the $\mathrm{pH}$ of the slurry to about 11 with a minimum contact time of 30 minutes (Westerhoff, 1978). If fly ash from power plants could be used successfully for conditioning alum sludge this would be beneficial to both industries. 


\section{Belt Filtration:-}

The belt press, or the belt filter press, consists of two endless filtration fabric belts held in close contact with each other by guide parallel rollers. The lower belt is made of coarse mesh fabric media consisting of twisted metal, plastic, or mixed fibers. The upper belt is solid. The conditioned sludge is fed onto the belt press at one end (draining zone) and is continuously dewatered by the pressure applied between the two belts (press zone and shear zone). The liquid drains off by gravity. The solids cake is scraped off by a blade at the other end of the belts.

A number of belt filter presses have been introduced. These devices have been used in Europe since the early 1960s for dewatering sewage sludge. In the United States, their use for dewatering water plant sludge in full-scale operations is not documented. Although belt presses are widely used in industries, especially in paper and pulp manufacturing, the process has also been successful for sewage sludge dewatering. (Technology \& Universit, 2016)

\section{Equipment description and operating principle:- Belt filters:-}

Most belt filters have the following characteristics:

A flocculator: Conditioning of sludge is necessary before it gets to the drainage zone. In the flocculator the sludge flocculants blend is done where the flocculated sludge is then evenly distributed on the filter bed. A gravity drainage zone: The flocculated sludge is drained on a first belt (lower belt) by simple gravity. The drainage is helped by picket fences that lay freely on the belt. In this zone a water line is created that corresponds roughly to the moment where the majority of the water freed by flocculation is eliminated. A progressive compression zone: The sludge, after drainage of the water freed by flocculation, is then pressed between two filter belts. With the arrival of the top belt, a progressive pressurization takes place:

1. Up to 4 bars for low-pressure belt filters.

2. Up to 5 bars for medium pressure belt filters.

3. Up to 7 bars for high-pressure belt filters.

A cake scraping zone: Once pressed, the sludge has a more solid aspect. It is called a sludge cake or simply cake. This cake is then scraped off from the surface of the two belts that separate at this level. A high pressure washing station: A bank of nozzles under 7 to 8 bars (100 to 120 PSI) level.

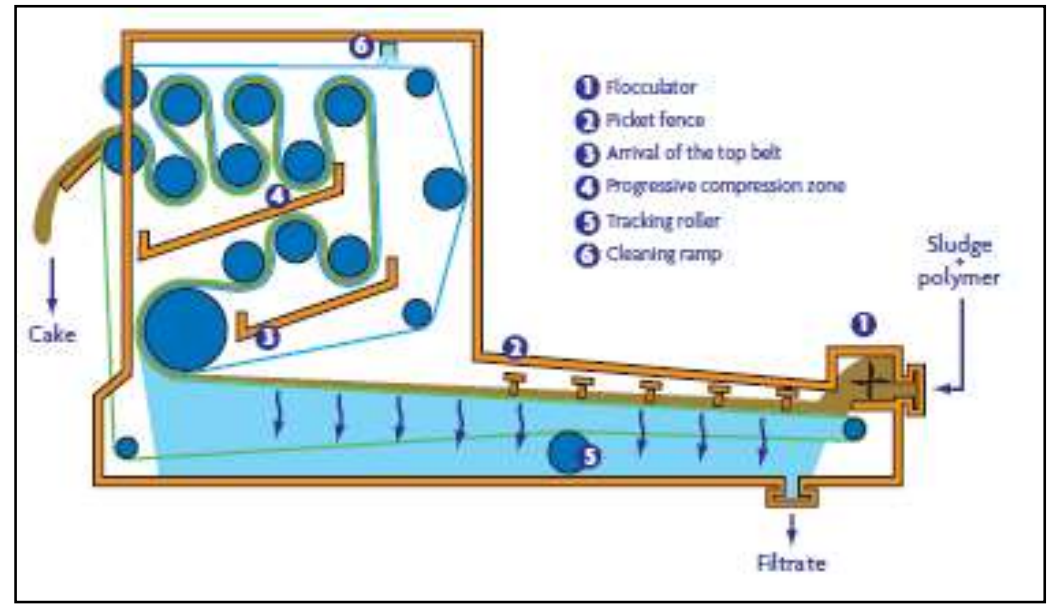

Figure 1(belt filter):-

Operation problems of belt filters:-

Sludge flocculation plays a major role in the end results, sludge flow filtrate quality and cake dryness. Checking of the quality of flocculation on belt filters is easy. Operation problems of belt filters include; Bad drainage: The sludge reaches the progressive compression zone without being fully drained, Sludge creep: In the compression zone, the sludge has a tendency to run away on the sides of the belt and Low cake dryness: The sludge cake's Dry Solids content is too low.

\section{Centrifuge dewatering machines:-}

This equipment uses the principle of a centrifuge, also known as centrifugal decanter, where by it uses a centrifugal force to accelerate solid-liquid separation.(Wakeman, 2007) In practice, the flocculated sludge is injected inside the 
centrifuge bowl through an injection pipe. The bowl has a high rotation speed $(3500 \mathrm{rpm})$ and the particles are flattened against the bowl's sides in the clarification zone. The particles are then pushed by an Archimedean screw towards the end of the bowl's cone in the sludge spin-dry zone. The clarified liquid centrate, is evacuated at the other end of the bowl by overflow.

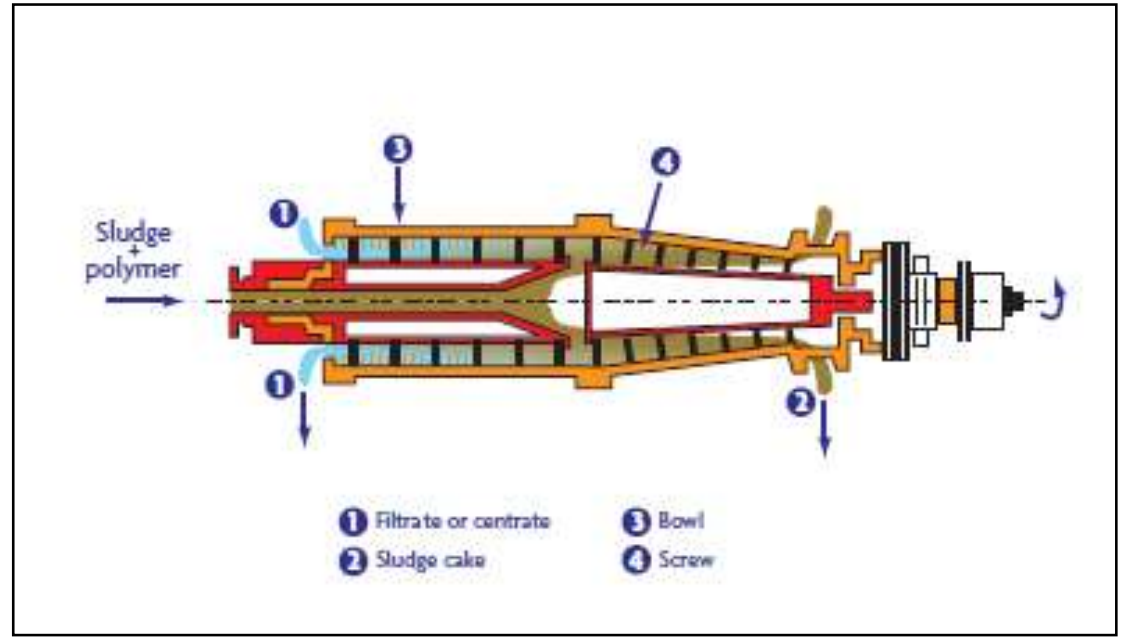

Figure 2:- (Continuous Solid Bowl Centrifuge).

\section{Operation problems of centrifuges:-}

Flocculation control in the centrifuge is more difficult than on a belt filter as the processes all takes place internally i.e. in the machine or pipe. Inside the centrifuge the flocs are put under an important force (2000g to $4000 \mathrm{~g}$ ). The flocs can be quickly destroyed if the polymer has not been well chosen or dosed. There are major operating problems such as Black centrate: The centrate has an unusual dark color. This color is due to the presence of numerous particles that are evacuated with the diaphragm overflow and are going back to the start of the process. Gray, foaming centrate: Only an excessive foaming is indicative of a problem. Slight foaming is a normal occurrence due to the high agitation level inside the centrifuge. Degasing eliminates this foam. Also Low dryness: The sludge cake has a lower than expected solids content

\section{Frame filter press dewatering:-}

Filtration is the most widely used method in the treatment of sludge produced by wastewater treatment. It can consist just in drainage though sand beds or it can be mechanical under vacuum middle or high pressure conditions which require more sophisticated equipment. Frame filter press dewatering will dewater sludge at a higher level of dryness than the previous techniques reviewed above. It is a discontinuous process that works in batch cycles.

\section{Working principle:-}

The sludge is pumped between plates that are covered with a filter cloth. The liquid seeps through the cloth, leaving the solids behind between the plates. The medium may or may not be precoated. When the spaces between the plates are filled, the plates are separated and the solids removed. The pressure exerted on the cake during formation is limited to the pumping force and filter closing system design. Filters are designed at pressures ranging from 50 to $225 \mathrm{Ib} /$ in2 (345 to $1550 \mathrm{kPa}$ ). As the final filtration pressure increases, a corresponding increase in dry cake solids is obtained. Most municipal sludges can be dewatered to produce 40 to 50 percent cake solids with 225-lb/in2 (690$\mathrm{kPa})$ filters. Filtrate quality will vary from $10 \mathrm{mg} / 1$ suspended solids with precoat to 50 to $500 \mathrm{mg} / 1$ with unprecoated cloth, depending on the medium, type of solids, and type of conditioning.

\section{Performance:-}

This equipment is almost suitable for all types of sludge. Hydrophilic organic sludge: inorganic conditioning is often recommended to enable satisfactory cake release due to minimal adherence to filter cloth. Hydrophilic inorganic sludge: the filer press generally requires the addition of lime only. Hydrophobic inorganic sludge: it is very dense and ideal for the filter press. It is dewatered without any preliminary conditioning and Oily sludge: the filter press can be used to treat sludge containing light oils, the presence of grease can sometimes impair the smooth running of the filter; clothes have to be degreased at frequent intervals. 


\section{Optimizing frame filter press:-}

For a frame filter press, the most frequent conditioning by far has been the combination of $\mathrm{FeCl} 3$ and lime. However presently, due to the ever-increasing volume of sludge to be disposed of, any unnecessary increase in sludge volume leads to unacceptable operating costs (too many operating cycles and too much sludge volume). These has necessitated the development of the new organic polymer conditioning process. However organic polymer conditioning possess some major problems; firstly Sticky cakes Instead of falling off by gravity when using organic polymers, the cake sticks to the filter cloth and an operator has to intervene during the opening phase. Secondly Cloth plugging: Pores get plugged, preventing the filtrate from passing through the cloth also Polymer efficiency loss: This phenomenon is often observed when the liquid sludge has been previously treated with lime. It results in a degradation of the flocs with time.

\section{Multi-screw press: Working principle:-}

The multi- screw press utilises the principles of dewatering force-water homo-direction and thin-layer dewatering. The machine allows automatic continuous operation of sludge flocculation thickening dewatering and filtrate discharging. The core dewatering drum includes the shaft drum, fixed rings and moving rings that aid in better dewatring of the sludge. The sludge enters the flocculation tank and it is mixed properly from where the perfectly flocculated sludge enters the dewatering drum which is rotating. The inner cubage of the rotary drum gets smaller and smaller as the rotation in the drum takes place. The filtrate flows out from the vents between the fixed and moving rings. Where the sludge is dewatered gradually under great pressure and sludge is later discharged from one end of the drum.(Kamami, 2011)

The pre-thickening device means that this technology has the potential to deal with a wide concentration of sludge ranging from $3000 \mathrm{mg} / \mathrm{l}$ to $5000 \mathrm{mg} / \mathrm{l}$. It is equipped with moving rings that are self-cleaning which prevents blocking issues that are often encountered when using traditional technology. The multi-plate screw press utilises very little power as it relies on a low inner pressure of the filter chamber and a rotating speed as low as $2-4 \mathrm{r} / \mathrm{min}$. The power consumption is as low as $0.01-0.1 \mathrm{kw} / \mathrm{h} / \mathrm{kg}$-DS only $1 / 8$ of belt presses and only $1 / 20$ of centrifugal machines. Moreover the problem of noise pollution is eradicated. A separate thickening tank is no longer needed as this technology can be connected directly to the aeration tank or the secondary sedimentation tank which greatly saves on space and capital costs. Elaspress Super-high Pressure Filter Press designed for advanced sludge dewatering for a low investment cost but with a high dewatering efficiency; approximately 3-4 times more efficient than the conventional filter press. The pressure is higher than that of the conventional membrane filter press and with a working cycle of 1.0-1.5h the working efficiency is 3-4 times better than the conventional membrane filter press. Furthermore this filter press does not need another pressure boosting device or other accessory devices. It uses fewer filter clothes which reduces the cost of maintaining this technology.("United States Environmental Protection Agency.(USEPA 2000). General Information on Biosolids. Retrieved from Environmental Protection Agency,” n.d.)

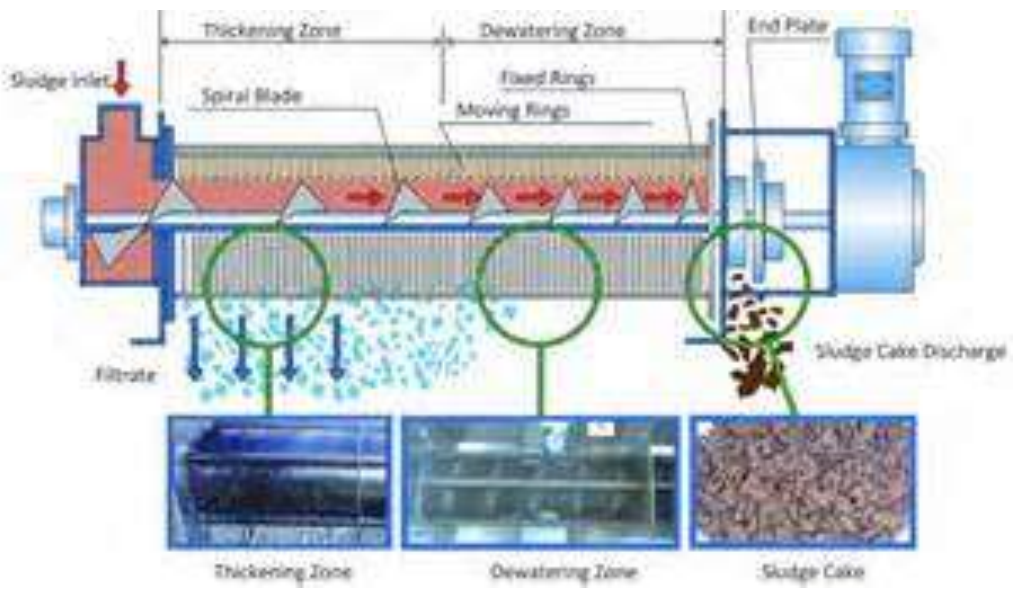

Figure 3:- (cross section of the Multi plate screw press).

This technology is very well suited for municipal wastewater plants etc. the Multi-plate Screw Press uses the Vertical Fibre Cloth Media Filter. Compared to traditional filters this technology consumes a low amount of energy it has a high filtration speed high capacity good effluent quality and a low operating cost. The machine only takes up a small space and can be applied for different types of waste water. It can be applied for the advanced treatment and upgrade of municipal sewage treatment rural and small town sewage treatment advanced treatment or reuse of industrial waste water pre-treatment of raw water purification of surface water pre-treatment of MBR and the 
treatment of circulation cooling water.(Okada, n.d.) Because the backwash uses mobile linear absorb-washing equipment which works simultaneously with the filtration process no storage water is needed. The effluent quality is good at SS less than $5 \mathrm{mg} / \mathrm{L}$ and it has a maximum load of SS $80-100 \mathrm{mg} / \mathrm{L}$. It can work automatically and all maintenance that is required is easy to do. This technology has been successfully applied in municipal sewage treatment town sewage treatment and industrial waste water treatment. If at all we need better technological designs in sludge dewatering Multi-plate Screw Press is the way forward. It ensures proper resource utilization and saves on operation and maintenance cost compared to other technologies. Compared to other equipment the Multi-plate Screw Press has more advantages and a better option as the paper further compares this technology to the already existing technology.(Okada, n.d.)

\section{Comparison Chart:-}

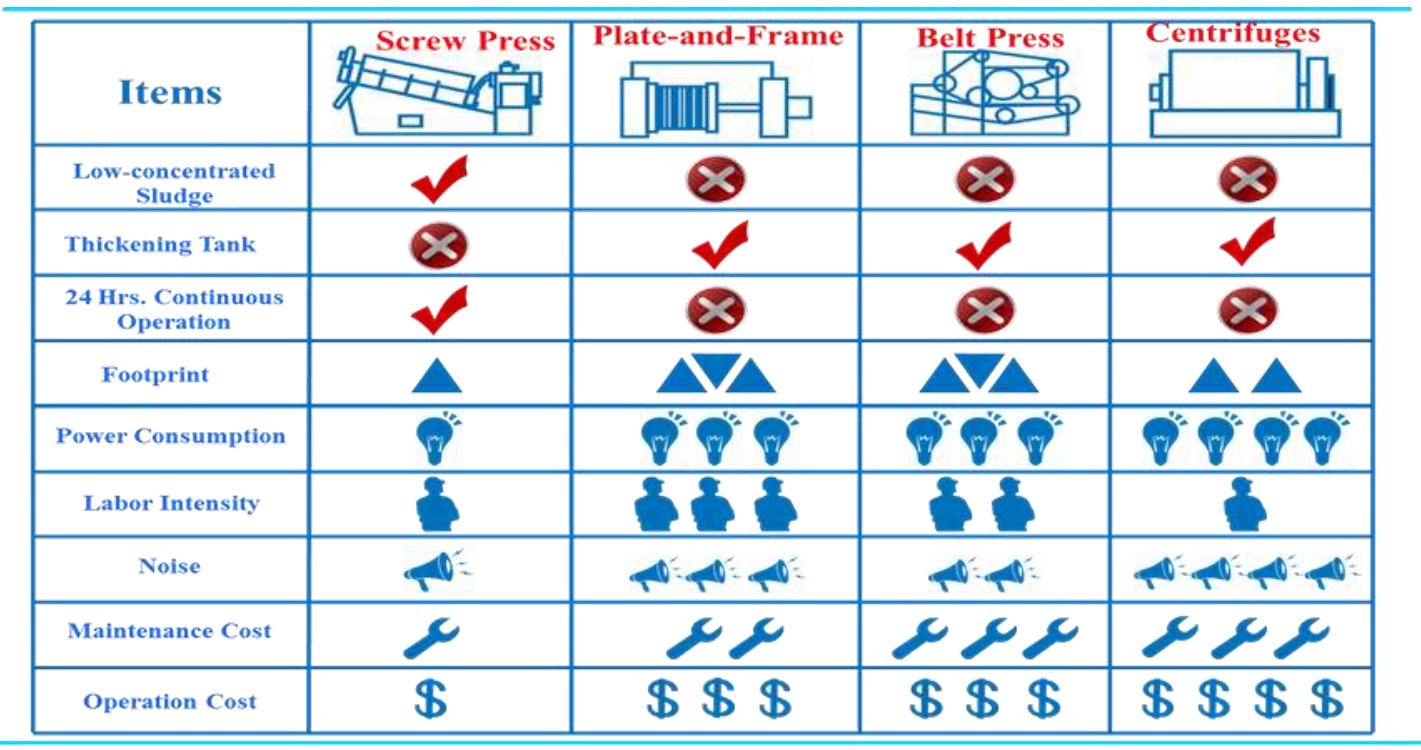

Table 1:- Comparison chart of the different machines available for sludge dewatering performance

Compared to other equipment as shown in the table below it is clear that the screw press has more advantages compared to the other equipment. Hence multi plate screw indeed is a better option when it comes to issues pertaining saving money, power consumption and even environmental considerations as this state of the art machine has better performance compared to its counterpart. This is the much needed equipment when it comes to the future as it is not only environmental friendly but also is modern.

\section{Conclusion:-}

Irrespective of the choice of method to treat sludge, the end product should be disposed of properly. Massive emphasis should be placed on minimizing the amount of sludge produced as well as maximizing the sludge content. The effect of various types of waste disposal on the environment should also be evaluated. In designing a water treatment plant, it is not adequate to consider only the optimization of various treatment unit operations and processes without giving due consideration to waste disposal. Plans for the handling and disposal of wastes should be included in the total design for a water treatment plant. This may be an important limiting or controlling factor. In choosing the equipment to handle and deal with sludge there should only be selection of equipment that is energy efficient in terms of operation, end product and labor.

While currently major technological advancements are occurring today, the treatment of water is a well-known process and is executed by state of the art techniques. The sludge resulting from this process represents the next challenge for the water treatment industry, in particular the minimizing of its volume. With the Multi plate screw press it is the best option for dewatering sludge and treating sludge as compared to the other equipment as explained above. 


\section{References:-}

1. Boráň, J., Houdková, L., \& Elsäßer, T. (2010). Processing of sewage sludge: Dependence of sludge dewatering efficiency on amount of flocculant. Resources, Conservation and Recycling, 54(5), 278-282. https://doi.org/10.1016/j.resconrec.2009.08.010

2. Bourioug, M., Alaoui-Sehmer, L., Laffray, X., Benbrahim, M., Aleya, L., \& Alaoui-Sossé, B. (2015). Sewage sludge fertilization in larch seedlings: Effects on trace metal accumulation and growth performance. Ecological Engineering, 77, 216-224. https://doi.org/10.1016/j.ecoleng.2015.01.031

3. Floerger, S. (2003). Sludge Dewatering, 35. https://doi.org/10.2524/jtappij.60.1698

4. Impact of water pollution on Nairobi river, Kenya. (n.d.).

5. Kamami, M. I. (2011). Fuzzy Based Decision Support Method for Selection of Sustainable Wastewater Treatment Technologies.

6. Mahmoud, A., Hoadley, A. F. A., Conrardy, J. B., Olivier, J., \& Vaxelaire, J. (2016). Influence of process operating parameters on dryness level and energy saving during wastewater sludge electro-dewatering. Water Research, 103, 109-123. https://doi.org/10.1016/j.watres.2016.07.016

7. Mech Dewater. (n.d.).

8. Okada, T. (n.d.). New Screw Press Sludge Dewatering Equipment Reduction of Sludge Moisture Content with a Minimum of Operator Maintenance.

9. Jerry A. Nathanson, MS, PE, Richard A. Schneider, MS, PE, Basic environmental technology: water supply, waste management, and pollution control/ Wisconsin.-Sixth edition

10. Sparks, T. (2012). Understanding filter presses and belt filters. Filtration and Separation, 49(4), $20-24$. https://doi.org/10.1016/S0015-1882(12)70193-3

11. Technology, E., \& Universit, O. (2016). The Prediction of Filter Belt Press Dewatering Efficiency for Activated Sludge By Experimentation on Filtration Compression ..., (March). https://doi.org/10.1080/09593332508618474

12. United States Environmental Protection Agency.(USEPA 2000). General Information on Biosolids. Retrieved from Environmental Protection Agency. (n.d.). Retrieved from https:/www.epa.gov/biosolids

13. Wakeman, R. J. (2007). Separation technologies for sludge dewatering. Journal of Hazardous Materials, 144(3), 614-619. https://doi.org/10.1016/j.jhazmat.2007.01.084

14. Warman, P. R., \& Termeer, W. C. (2005). Evaluation of sewage sludge, septic waste and sludge compost applications to corn and forage: Yields and N, P and K content of crops and soils. Bioresource Technology, 96(8), 955-961. https://doi.org/10.1016/j.biortech.2004.08.003

15. United States Environmental Protection Agency. (USEPA 2000). General Information on Biosolids. Retrieved from Environmental Protection Agency www.epa.gov/owm/mtb/bosolids/genqa.htm. 